\title{
ANALISIS KESEDIAAN MEMBAYAR WILLINGNESS TO PAY (WTP) KONSUMEN TERHADAP PRODUK BATIK TULIS KHAS JOMBANG
}

\section{Listiani Hidayah ${ }^{1}$ \\ Teknik Industri, Fakultas Teknik, Universitas Hasyim Asy'ari listianihidayah@gmail.com}

Fatma Ayu Nuning Farida Afiatna ${ }^{2}$ Teknik Industri, Fakultas Teknik, Universitas Hasyim Asy'ari fatmaayu2511@gmail.com

\section{Published By: \\ Program Study Teknik Industri \\ Universitas Hasyim Asy'ari \\ Tebuireng Jombang. \\ Email: \\ invantri.unhasy@gmail.com \\ Phone : \\ (0321) 861719}

\section{Map \& Adreess :}

Tebuireng, Jl. Irian Jaya No.55, Cukir, Kec.

Diwek, Kabupaten Jombang, Jawa Timur 61471

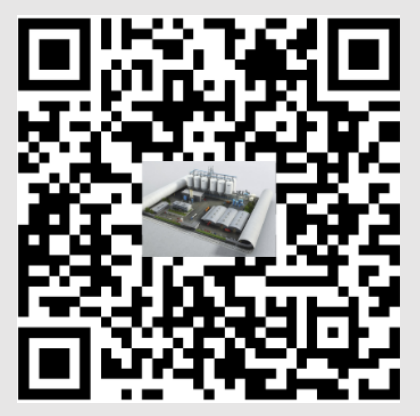

\section{Abstract}

In determining the selling price, it is important to know how much consumers' willingness to pay (WTP) to get Jombang Typical Batik Tulis products with better quality. In this regard, this study aims to determine the maximum average value of WTP that consumers are willing to pay in buying Batik Tulis Jombang Typical and to find out the significant factors that affect the WTP of Batik Tulis Jombang typical consumers. This study took a sample of 40 respondents who were consumers of Jombang's typical written batik products, and were selected using the purposive sampling method. The data were analyzed using the contingent valuation method (CVM) analysis and using multiple linear regression analysis. The results showed that the maximum average value of WTP for consumers of Batik Tulis Jombang typical was Rp 555,250.00 per piece. Among them, the factors that significantly influence consumers' willingness to pay are gender, income and price.

Keywords: batik tulis, CVM, WTP, multiple, linear, regression

DOI : $X X X-X X X X-X X X X$

Article History,

Submit : 05 April 2019

Received in from: 05 April 2019

Accepted : 08 April 2019

Available online: 30 April 2019 


\begin{abstract}
Abstrak
Dalam penentuan harga jual penting untuk diketahui seberapa besar kesediaan konsumen untuk membayar atau willingness to pay (WTP) untuk mendapatkan produk Batik Tulis Khas Jombang dengan kualitas yang lebih baik. Berkaitan dengan hal tersebut maka penelitian ini bertujuan untuk menentukan besarnya nilai rata-rata WTP maksimum yang bersedia dibayarkan oleh konsumen dalam membeli Batik Tulis Khas Jombang dan untuk mengetahui faktor-faktor signifikan yang mempengaruhi WTP konsumen batik tulis khas Jombang. Penelitian ini mengambil sampel 40 responden yang merupakan konsumen dari produk batik tulis khas Jombang, dan dipilih menggunakan metode Purposive Sampling. Data di analisis menggunakan analisis contingent valuation method (CVM) dan menggunakan analisis regresi linier berganda. Hasil penelitian menunjukkan bahwa nilai rata-rata maksimum WTP konsumen batik tulis khas Jombang sebesar Rp 555.250,00 per potong. Diantaranya faktor yang signifikan berpengaruh terhadap kesediaan membayar konsumen adalah jenis kelamin, pendapatan dan harga.
\end{abstract}

Kata Kunci: Batik tulis, CVM, WTP, regresi linier berganda

\section{PENDAHULUAN}

Batik telah ditetapkan sebagai warisan dunia asli Indonesia oleh UNESCO pada tanggal 2 Oktober 2009 dan diperingati sebagai Hari Batik Nasional. Menurut KBBI (2008:146) batik merupakan kain bergambar yang pembuatannya secara khusus dengan menuliskan atau menerakan malam pada kain, kemudian mengolahnya melalui proses tertentu. Batik juga merupakan warisan budaya yang harus dijaga dan dikembangkan.

Seorang perintis batik Jombang yang terkenal dengan motif Candi Rimbi dan Ringin Contong bernama ibu $\mathrm{Hj}$. Maniati. Beliau adalah orang pertama yang merintis batik khas Jombang, yang kini motifnya digunakan seluruh instantsi baik negeri maupun swasta di Jombang (Anggi Fridianto, Jawa Pos Radar, 2020). Batik Jombangan juga pernah diikutkan dalam Indonesia Fashion Week (IFW) 2015 di Jakarta Convention Centre Senayan. Batik Jombangan buatan ibu Maniati juga sudah go internasional, hal tersebut terjadi setelah Batik Jombangan diikutkan dalam sebuah pameran di Tokyo Jepang dan Yordania Timur Tengah menurut Ibu Ririn putri dari ibu Hj. Maniati.
Konsumen batik tulis khas Jombang paling banyak berasal dari kota Jombang.Meskipun dari luar kota juga ada namun tidak sebanyak dari kota Jombang kata salah satu karyawan di Sekar Jati Star. Produk Batik tulis Khas Jombang biasanya digunakan untuk seragam dinas, seragam sekolah maupun acara resmi lainnya menurut ibu Siti Zulaikha penjaga toko batik di Sekar Jati Star Jatipelem Jombang.

Masyarakat Jombang memprioritaskan faktor harga maupun kualitas produk batik tulis. Pemilik usaha batik tulis khas jombang juga memaksimalkan harga sesuai dengan pengeluarannya dalam pengolahan produknya. Karena biaya pengiriman bahan baku batik dari luar kota dan berkurangnya tenaga kerja yang menggeluti batik. Jadi tidak heran jika harga batik tulis khas Jombang perpotong (2,3 meter) mencapai Rp 500.000,00 - Rp 1.500.000,00.

Persepsi mengenai harga batik tulis khas Jombang yang dianggap mahal menjadi salah satu pemicu penurunan tingkat jual bagi produsen, oleh karena itu dalam penentuan harga jual penting untuk diketahui seberapa besar kesediaan konsumen untuk membayar atau willingness to pay (WTP) untuk membeli 
produk Batik Tulis Khas Jombang dengan peningkatan kualitas yang lebih baik.

Berdasarkan permasalahan yang ada rumusan masalah dalam penelitian ini adalah 1 ) Berapa besarnya nilai rata-rata WTP maksimum yang bersedia dibayarkan oleh konsumen dalam membeli Batik Tulis Khas Jombang menggunakan metode contingent valuation method (CVM). 2) Apa saja faktorfaktor yang secara signifikan mempengaruhi WTP konsumen batik tulis khas Jombang menggunakan regresi linier berganda.

Tujuan penelitian ini adalah untuk menentukan besarnya nilai rata-rata WTP maksimum yang bersedia dibayarkan oleh konsumen dalam membeli Batik Tulis Khas Jombang menggunakan metode contingent valuation method (CVM) dan untuk mengetahui faktor-faktor signifikan yang mempengaruhi WTP konsumen batik tulis khas Jombang menggunakan regresi linier berganda.

\section{METODE}

Berikut ini adalah diagram alur penelitian analisis kesediaan membayar konsumen produk batik tulis khas Jombang di Sekar Jati Star :

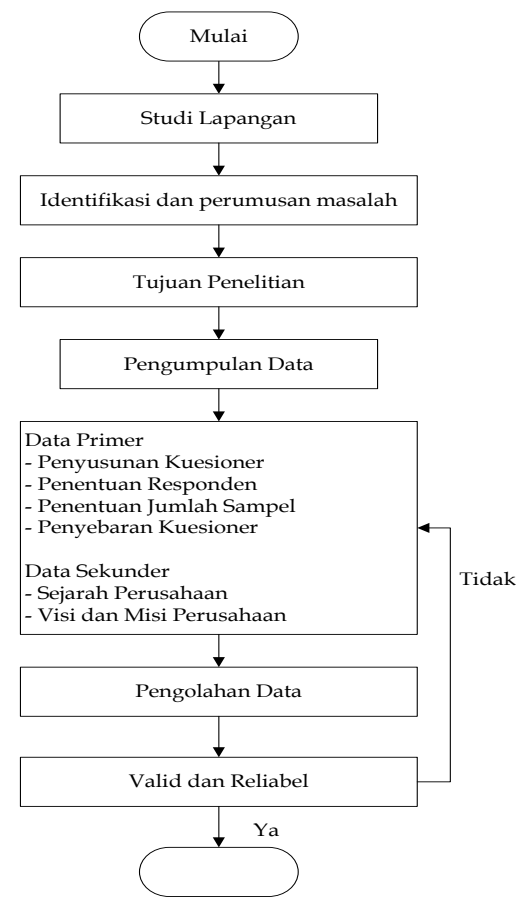

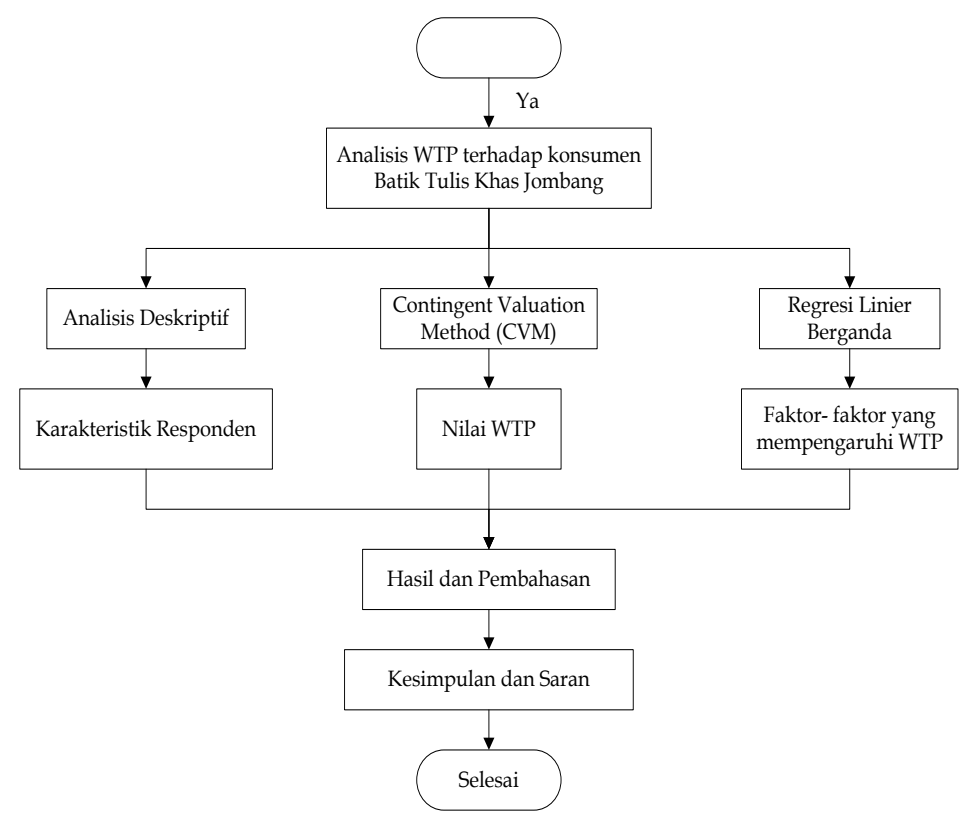

1. Metode Penentuan Lokasi Penelitian

Penelitian di laksanakan di UKM Batik Sekar Jati Star di Jatipelem Diwek Jombang. Untuk lokasi pembagian kuesioner dibagikan kepada konsumen batik tulis yang berasal dari kota Jombang. Hal tersebut ditentukan secara Purposive Sampling yaitu dipilih berdasarkan pertimbangan bahwa lokasi ini memiliki penjualan produk batik tulis khas Jombang terbanyak menurut pemilik UKM Batik Sekar Jati Star. Penelitian ini dilaksanakan pada 01 sampai 31 Maret 2021.

2. Metode Penentuan Sampel Penelitian

Penelitian ini menggunakan metode purposive sampling dalam mengambil sampel konsumen batik tulis khas Jombang. Hal ini sesuai dengan pendapat Sujarweni pada penelitian Risma Dwi Komala dan Nellyningsih (2017) bahwa Sampling Purposive merupakan teknik pengambilan sampel dengan pertimbangan atau kriteriakriteria.

Dalam menentukan besarnya ukuran sampel digunakan statistik deskriptif dengan menggunakan rumus Slovin (1960) yaitu sebagai berikut : 


$$
n=\frac{N}{1+N(e)^{2}}
$$

Keterangan :

$\mathrm{n}=$ ukuran sampel

$\mathrm{N}=$ ukuran populasi

$\mathrm{e}=$ persentase kelonggaran ketidaktelitian karena kesalahan pengambilan sampel yang masih dapat ditolerir atau diinginkan (5\% atau 0,05).

Berdasarkan perhitungan pada rumus slovin (1960), didapatkan hasil yaitu 41,2 sampel yang dibulatkan menjadi 40 responden. Hal ini disesuaikan berdasarkan teori Roscoe dalam Sugiyono pada penelitian RR Chyntia Ramadhani Febrita (2017) yang menyatakan bahwa ukuran sampel yang layak dalam penelitian adalah antara 30 sampai dengan 500. Dengan jumlah sampel yang kecil, maka peneliti mengambil besaran tingkat ketelitian dan kesalahan maksimal yaitu 5\% $(0,05)$.

3. Jenis dan Sumber Data

Dalam Penelitian ini jenis data yang digunakan adalah data primer dan data sekunder. Data primer diperoleh dengan melakukan wawancara dengan responden dengan bantuan kuesioner. Sedangkan data sekunder diperoleh dari pemilik UKM Batik Sekar Jati Star. Serta juga diperoleh dari literatur-literatur yang relavan dengan topik penelitian ini.

4. Metode Analisis Data

Analisis CVM dilakukan dengan berbagai tahap yaitu membuat pasar hipotesis, menentukan nilai lelang (bidding games), menghitung nilai rata- rata WTP, mengestimasi kurva WTP dan agresi WTP menurut Fauzy pada penelitian Lely Diana Sari Saputri (2018).

a. Memperkirakan Nilai Rata-rata WTP (Calculating Average WTP)
$E W T P=\frac{\sum_{i=1}^{n} W i}{n}$

Dimana :

EWTP = Rata-rata nilai WTP pengunjung

$\mathrm{Wi}=$ besar WTP yang bersedia dibayarkan

$\mathrm{i} \quad=$ responden yang bersedia membayar

n = jumlah responden

b. Menjumlahkan Data (Agregating Data)

$$
T W T P=\sum_{i=0}^{n} W T P i n i
$$

Keterangan :

TWTP = Total WTP

$\mathrm{WTPi}=\mathrm{WTP}$ individu sampel ke-i

ni $=$ Jumlah ke-i yang bersedia membayar WTP

$\mathrm{i}=$ Responden ke-i yang bersedia membayar

Analisis regresi linier berganda yang dinyatakan dalam bentuk fungsi sebagai berikut :

$Y=a+b 1 X 1+b 2 \times 2+b 3 \times 3+b 4 \times 4+b 5 \times 5+$ b6 66

Keterangan :

$\mathrm{Y}=$ Willingness To Pay

a = bilangan konstanta

b1 = koefisien korelasi jenis kelamin

$\mathrm{X} 1$ = jenis kelamin

b2 = koefisien korelasi usia

$\mathrm{X} 2$ = usia

b3 = koefisien korelasi status perkawinan

X3 = status perkawinan

b4 = koefisien korelasi pendidikan terakhir

$\mathrm{X} 4$ = pendidikan terakhir

b5 = koefisien korelasi pendapatan

X5 = pendapatan

b6 = koefisien korelasi harga

X6 = harga 
Untuk mengetahui apakah hipotesis yang diajukan dalam penelitian ini diterima atau ditolak maka akan dilakukan pengujian hipotesis dengan menggunakan Uji $t$ dan Uji $F$. Uji $t$ digunakan untuk mengetahui pengaruh masing-masing variabel independen terhadap variabel dependen menurut Widjarjono pada penelitian Hendri dan Roy Setiawan (2017). Sedangkan pada Uji F digunakan untuk menguji signifikan tidaknya pengaruh variabel bebas secara simultan terhadap variabel terikat menurut Kuncoro pada penelitian Hendri dan Roy Setiawan (2017).

\section{HASIL DAN PEMBAHASAN}

A. Karakteristik Responden

Pada penelitian ini mengambil 40 responden yang berasal dari konsumen Batik Tulis Sekar Jati Star yang ada di Jatipelem Jombang. Berdasarkan hasil survey dengan media online melalui kuesioner dalam bentuk google form karena terkait adanya Pandemi Covid-19 didapatkan hasil yang berbeda-beda pada setiap karakteristik responden yang diukur. Menurut Hamzoui dan Zahaf pada penelitian Vickitra Aufanada, T.Ekowati, W.D Prastiwi (2017) menyatakan bahwa meskipun diasumsikan bahwa karakteristik yang dimiliki oleh suatu produk objektif dan sama untuk konsumen, setiap konsumen memiliki perilaku berbeda yang berkaitan dengan pembelian produk tersebut.

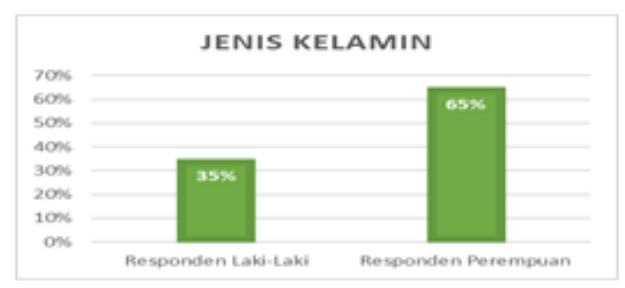

Gambar 1. Grafik Karakteristik Responden Berdasarkan Jenis Kelamin

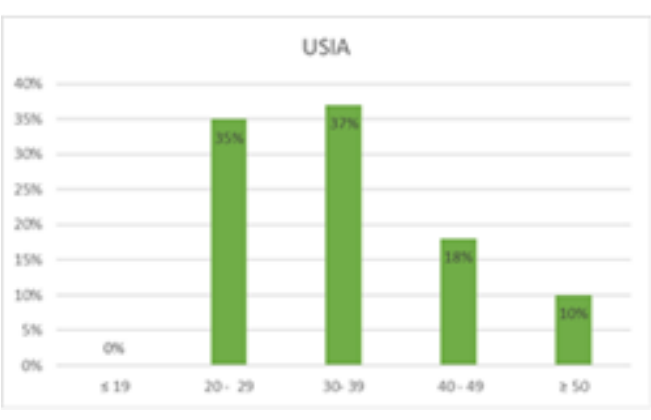

Gambar 2. Grafik Karakteristik Responden Berdasarkan Usia

Pada grafik pada gambar 1 dapat dilihat bahwa dari 40 responden yang diteliti, terdapat sebanyak $65 \%$ responden berjenis kelamin perempuan dan sisanya sebesar 35\% adalah responden adalah lakilaki. Hal ini dalam artian konsumen lebih banyak jenis kelamin perempuan karena pada dasarnya perempuan lebih sering berbelanja membeli kain batik tulis untuk kebutuhan sandang nya.

Pada gambar 2 dapat dilihat bahwa tidak ada konsumen berusia $\leq 19$ tahun atau sebesar $0 \%$, sebanyak $35 \%$ berusia antara 20 29 tahun, sebanyak 37\% berusia antara 30-39 tahun, sebanyak $18 \%$ berusia antara $40-49$ tahun, dan sebanyak $10 \%$ berusia $\geq 50$ tahun. Hasil survei terbaru dari lembaga Snapcart pada Januari 2018 juga mengungkapkan pembelanja terbanyak berasal dari usia 25-35 tahun. Oleh karena itu, dalam penelitian ini konsumen paling banyak pada usia 30-39 tahun sebanyak $47 \%$.

Status pernikahan juga menjadi salah satu faktor pemicu seseorang untuk berbelanja membeli kain batik tulis. Seseorang yang sudah menikah lebih cenderung menjadi bagian terbesar konsumen batik tulis khas Jombang karena biasanya kain batik tulis khas Jombang ini digunakan untuk pakaian resmi untuk menghadiri acara hajatan ataupun acara keluarga lainnya. Ada juga pemesan dari sekolahan tertentu untuk seragam sekolah, 
seragam kantor maupun seragam dinas menurut ibu Siti Zulaikha selaku penjaga toko batik di Sekar Jati Star. Berikut ini adalah rekapitulasi data 40 responden berdasarkan status pernikahan :

Tabel 1. Data Responden Berdasarkan

\begin{tabular}{cccc}
\hline No & Status & $\begin{array}{c}\text { Jumlah } \\
\text { (orang) }\end{array}$ & $\begin{array}{c}\text { Persentase } \\
\text { (\%) }\end{array}$ \\
\hline $\mathbf{1}$ & $\begin{array}{c}\text { Sudah } \\
\text { Menikah }\end{array}$ & 32 & $80 \%$ \\
\hline $\mathbf{2}$ & $\begin{array}{c}\text { Belum } \\
\text { Menikah }\end{array}$ & 8 & $20 \%$ \\
\hline
\end{tabular}

Dari Tabel 1 , dapat diketahui bahwa sebanyak $80 \%$ responden dengan status sudah menikah dan sebanyak 20\% responden dengan status sudah menikah.

Tingkat pendidikan yang lebih tinggi juga berpengaruh terhadap pemahaman dan rasa ingin tahu seseorang terhadap produk batik tulis khas Jombang. Berikut ini adalah rekapitulasi data 40 responden berdasarkan tingkat pendidikan :

Tabel 2. Data Responden Berdasarkan Tingkat Pendidikan

\begin{tabular}{cccc}
\hline No & $\begin{array}{c}\text { Pendidikan } \\
\text { Terakhir }\end{array}$ & $\begin{array}{c}\text { Jumlah } \\
\text { (Orang) }\end{array}$ & $\begin{array}{c}\text { Persentase } \\
\mathbf{( \% )}\end{array}$ \\
\hline $\mathbf{1}$ & SD/MI & 1 & $2 \%$ \\
\hline $\mathbf{2}$ & SMP/MTS & 1 & $2 \%$ \\
\hline $\mathbf{3}$ & SMA/SMK & 29 & $73 \%$ \\
\hline $\mathbf{4}$ & Diploma & 2 & $5 \%$ \\
\hline $\mathbf{5}$ & Sarjana & 7 & $18 \%$ \\
\hline
\end{tabular}

Pada tabel 2, dapat dilihat bahwa pendidikan yang mayoritas terdapat pada responden yaitu tingkat SMA/SMK yaitu sebanyak 73\%. Sebanyak 18\% tingkat pendidikannya Sarjana, 5\% Diploma, dan sebanyak $2 \%$ tingkat pendidikannya adalah SD/MI dan SMP/MTS.

Berikut ini adalah rekapitulasi data 40 responden berdasarkan tingkat pendapatan:
Tabel 3. Data Responden Berdasarkan Tingkat Pendapatan

\begin{tabular}{cccc}
\hline No & Pendapatan & $\begin{array}{c}\text { Jumlah } \\
\text { (orang) }\end{array}$ & $\begin{array}{c}\text { Persentase } \\
(\%)\end{array}$ \\
\hline $\mathbf{1}$ & $\begin{array}{c}\text { kurang dari 1 } \\
\text { juta }\end{array}$ & 6 & $15 \%$ \\
\hline $\mathbf{2}$ & $\begin{array}{c}\text { 1 juta - } 2,6 \\
\text { juta }\end{array}$ & 9 & $22 \%$ \\
\hline $\mathbf{3}$ & $\begin{array}{c}2,7 \text { juta }-4,3 \\
\text { juta }\end{array}$ & 17 & $43 \%$ \\
\hline $\mathbf{4}$ & $\begin{array}{c}\text { lebih dari } \\
\text { 4,3 juta }\end{array}$ & 8 & $20 \%$ \\
\hline
\end{tabular}

Berdasarkan tabel 3,dapat dilihat bahwa sebanyak $15 \%$ responden berpendapatan kurang dari 1 juta, responden berpendapatan rentang antara 1 juta - 2,6 juta sebanyak $22 \%$, responden berpendapatan rentang antara 2,7 juta $-4,3$ juta sebesar $43 \%$ dan lebih dari 4,3 juta sebesar $20 \%$. Hal ini menunjukkan bahwa konsumen Batik Tulis Khas Jombang di Sekar Jati Star terdiri dari semua kalangan masyarakat, baik tingkat bawah, menengah maupun tingkat atas.

B. Analisis Tingkat Kesediaan Membayar Konsumen

Analisis WTP (Willingness To Pay) dilakukan untuk mengetahui nilai kesediaan membayar atau nilai maksimum yang dikeluarkan seseorang terhadap produk Batik Tulis Khas Jombang di Sekar Jati Star. Responden Penelitian ini berjumlah 40 orang dan 85\% diantaranya bersedia membayar untuk peningkatan kualitas produk Batik Tulis Khas Jombang. Sisanya 15\% tidak bersedia membayar atas peningkatan kualitas tersebut.

Kesediaan membayar pada konsumen batik tulis khas Jombang, di analisis menggunakan CVM yang terdiri dari enam tahapan menurut Hanley dan Spash pada penelitian Muhammad Fauzi (2010) sebagai berikut :

1) Membangun Pasar Hipotetik 
Memberikan informasi mengenai peningkatan kualitas dari produk Batik Tulis Khas Jombang, sehingga responden mengetahui gambaran tentang situasi pasar hipotetik yang dimaksud. Hal tersebut dilakukan agar responden bisa menentukan jumlah uang yang bersedia dibayarkan untuk produk batik tulis khas Jombang.

2) Memperoleh Nilai Penawaran WTP (Obtaining Bids)

Pada hasil rekapitulasi responden sebanyak $23 \%$ hanya menginginkan harga kurang dari Rp 500.000,00 dan sebesar 77\% responden menginginkan harga 500 ribu - 1 juta. Hal ini dapat diartikan bahwa konsumen batik tulis di Sekar Jati Star bersedia membayar untuk peningkatan kualitas produk produk batik tulis khas Jombang dengan rentang harga 500 ribu - 1 juta.

3) Menghitung Dugaan Nilai Rataan WTP

Berikut adalah dugaan nilai rataan WTP responden untuk membeli produk batik tulis khas Jombang per potong (2,3 meter) berdasarkan hasil kuesioner oleh 40 responden sebagai berikut :

Tabel 4. Rata-rata WTP pada responden

\begin{tabular}{ccccc} 
No & $\begin{array}{c}\text { Keteran } \\
\text { gan }\end{array}$ & $\begin{array}{c}\text { Rata-Rata } \\
\text { WTP dari } \\
\text { Responden }\end{array}$ & $\begin{array}{c}\text { Jumla } \\
\mathbf{h} \\
\text { Respo } \\
\text { nden }\end{array}$ & $\begin{array}{c}\text { WTP x } \\
\text { Jumlah } \\
\text { Responden }\end{array}$ \\
\hline $\mathbf{1}$ & $\begin{array}{c}\text { kurang } \\
\text { dari } 500 \\
\text { ribu }\end{array}$ & Rp 250.000 & 7 & Rp 1.750 .000 \\
\hline $\mathbf{2}$ & $\begin{array}{c}500 \\
\text { ribu- } \\
\text { 1juta }\end{array}$ & Rp 570.000 & 14 & $\begin{array}{c}\text { Rp } \\
20.460 .000\end{array}$ \\
\hline \multicolumn{2}{c}{ Total } & 40 & $\begin{array}{c}\text { Rp } \\
\mathbf{2 2 . 2 1 0 . 0 0 0}\end{array}$ \\
\hline
\end{tabular}

Berdasarkan tabel 4. diperoleh nilai rata-rata WTP responden sebesar Rp 555.250,00. Jadi responden bersedia membayar 11\% lebih tinggi dari harga awal. Nilai rata-rata WTP responden tersebut dapat dijadikan sebagai acuan bagi produsen dalam menentukan harga jual produk batik tulis khas Jombang di Sekar Jati Star.

4) Menduga Kurva WTP

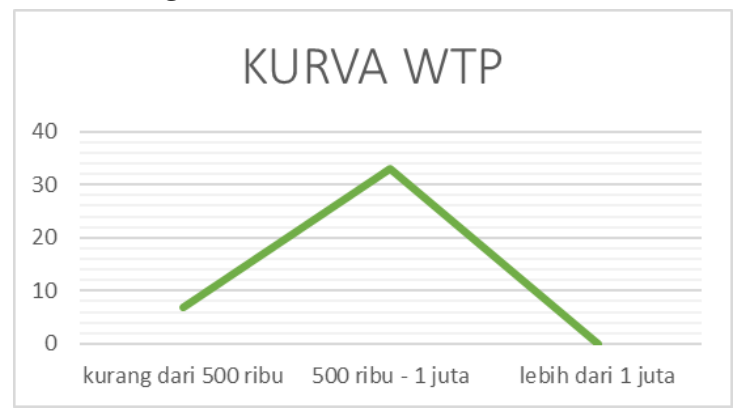

Gambar 3. Kurva Kesediaan Membayar Konsumen

Batik Tulis Khas Jombang di Sekar Jati Star

Kurva WTP responden dibentuk berdasarkan tingkat WTP yang bersedia dibayarkan dengan jumlah responden yang bersedia membayar. Dapat dilihat pada kurva WTP di atas jika penawaran harga pada konsumen hanya bersedia di rentang harga kurang dari 500 ribu dan 500 ribu-1 juta, tidak ada responden yang bersedia membayar dengan harga lebih dari 1 juta.

5) Menentukan Total WTP

Nilai total WTP dapat diperoleh dari perkalian rata-rata WTP responden dengan jumlah populasi konsumen batik tulis di Sekar Jati Star. Dengan rata-rata jumlah populasi adalah 46 orang sesuai pada data penjualan batik tulis di Sekar Jati Star. Diperoleh nilai total WTP seperti tabel 5 sebagai berikut :

Tabel 5. Total WTP

\begin{tabular}{ccc}
$\begin{array}{c}\text { Nilai Rataan } \\
\text { WTP }\end{array}$ & $\begin{array}{c}\text { Rata-rata } \\
\text { Populasi }\end{array}$ & Nilai Total WTP \\
\hline Rp 555.250 & 46 & Rp 25.541.500 \\
\hline
\end{tabular}

6) Evaluasi Pelaksanaan CVM

Pelaksanaan CVM pada penelitian dievaluasi berdasarkan nilai $\mathrm{R}$ Square yang dihasilkan oleh model. Hasil analisis regresi linier berganda dihasilkan $\mathrm{R}$ Square sebesar $84,4 \%$ yang menunjukan jika hasil pelaksanaan cukup baik yang dapat diyakini kebenaran dan keandalannya. Hal ini sesuai 
dengan pernyataan Deny Kurniawan (2008) yaitu semakin besar nilai R2 maka semakin baik model regresi yang diperoleh.

C. Faktor-faktor yang Mempengaruhi Kesediaan Membayar

1. Uji F (simultan)

\begin{tabular}{|c|c|c|c|c|c|c|}
\hline \multicolumn{7}{|c|}{ ANOVA' } \\
\hline & & $\begin{array}{c}\text { Sum of } \\
\text { Squares }\end{array}$ & df & Mean Square & $\mathrm{F}$ & Sig. \\
\hline \multirow[t]{3}{*}{1} & Regression & 1085652.120 & 6 & 180942.020 & 29.733 & $.000^{2}$ \\
\hline & Residual & 200825.380 & 33 & 6085.618 & & \\
\hline & Total & 1286477.500 & 39 & & & \\
\hline
\end{tabular}

Gambar 4. Hasil Output Uji F Menggunakan SPSS 16.0

Berdasarkan hasil output SPSS diatas, diketahui nilai Sig. adalah sebesar 0,000. Karena nilai Sig. 0,000 < 0,05, maka sesuai dengan dasar pengambilan keputusan uji $\mathrm{F}$ dapat disimpulkan bahwa prediktor (harga, pendapatan, status perkawinan, jenis kelamin, usia, dan pendidikan terakhir) secara simultan berpengaruh terhadap Willingness To Pay (WTP).

Berdasarkan perbandingan nilai $\mathrm{F}$ hitung dengan $\mathrm{F}$ tabel diketahui nilai $\mathrm{F}$ hitung adalah sebesar 29,733. Karena nilai F hitung 29,733 > $F$ tabel 2,34 maka sesuai dengan dasar pengambilan keputusan uji $F$ dapat disimpulkan bahwa prediktor (harga, pendapatan, status perkawinan, jenis kelamin, usia, dan pendidikan terakhir) secara simultan berpengaruh terhadap Willingness To Pay (WTP).

\section{Uji t (Parsial)}



Gambar 5. Hasil Output Uji t Menggunakan SPSS 16.0

Berdasarkan hasil output diatas dapat diketahui bahwa variabel yang memperoleh hasil mempengaruhi kesediaan membayar konsumen secara signifikan adalah variabel jenis kelamin, pendapatan dan harga. Sementara variabel yang tidak signifikan mempengaruhi kesediaan membayar yaitu variable usia, status perkawinan, dan pendidikan terakhir.

Variabel jenis kelamin berpengaruh signifikan terhadap WTP dengan nilai signifikan $0,013<0,05$. Hubungan positif tersebut menunjukkan bahwa jenis kelamin (laki-laki dan perempuan) berpengaruh dalam kesediaan membayar produk batik tulis khas jombang di Sekar Jati Star. Seperti pada penelitian Fatha Fajria, Dyah Ethika dan Djeimy Kusnaman (2020) faktor-faktor yang mempengaruhi kesediaan membayar salah satunya adalah jenis kelamin.

Variabel pendapatan memperoleh nilai signifikansi sebesar 0,010 ( $\mathrm{p}$ sig.< a) sehingga menunjukkan bahwa variabel pendapatan secara signifikan mempengaruhi kesediaan membayar konsumen. Hasil tersebut mengkonfimasi hasil penelitian Priambodo dan Najib (2014) pada jurn yang menemukan bahwa semakin tinggi tingkat pendapatan konsumen, maka diduga semakin besar pula kesediaan membayar.

Variabel harga memperoleh signifikansi sebesar 0,000 ( $p$ sig. $<\alpha$ ) dengan nilai a sebesar 0,05 , sehingga menunjukkan bahwa variabel harga secara signifikan mempengaruhi kesediaan membayar konsumen dalam membeli produk batik tulis khas Jombang.

\section{PENUTUP}

\section{Simpulan}

Konsumen produk batik tulis khas Jombang di Sekar Jati Star didominasi oleh konsumen perempuan sebesar 65\%, dengan rata-rata usia 30-39 tahun, dengan latar belakang pendidikan lulusan SMA/SMK sederajat, sudah menikah, dan memiliki pendapatan perbulan dengan rentang $\mathrm{Rp}$ 
2.700.000,00 - Rp 4.300.000,00 . Sebagian besar konsumen batik tulis khas jombang memberikan penilaian yang baik terhadap produk batik tulis khas jombang di Sekar Jati Star, sehingga konsumen batik tulis khas jombang sebesar $85 \%$ bersedia membayar lebih tinggi jika kualitas produk batik tulis khas Jombang ditingkatkan. Nilai rata-rata maksimum WTP konsumen batik tulis khas Jombang sebesar Rp 555.250,00 per potong atau setiap pembelian 2,3 meter kain batik tulis khas Jombang.

Willingness To Pay (WTP) atau kesediaan membayar konsumen terhadap produk batik tulis khas Jombang dipengaruhi oleh berbagai faktor. Dalam hasil perhitungan Uji F dan Uji t diantaranya faktor yang signifikan berpengaruh terhadap kesediaan membayar konsumen adalah jenis kelamin, pendapatan dan harga.

\section{Saran}

Pada penelitian mengenai kesediaan membayar konsumen terhadap produk batik tulis Khas Jombang selanjutnya adalah agar dapat meneliti kesediaan membayar konsumen yang membeli produk Batik Tulis khas Jombang diberbagai tempat serta dapat juga menambahkan variabel - variabel lain yang mempengaruhi kesediaan membayar konsumen.

\section{DAFTAR PUSTAKA}

Anggi Fridianto.(2020), "Maniati, Sang Perintis Batik Khas Jombang". darjombang.jawapos.com. Diakses pada 08 Maret 2021 pukul 18.30 WIB.

Departemen Pendidikan Indonesia (2008). Kamus Besar Bahasa Indonesia. Jakarta: Balai Pustaka.

Fatha Fajria, dkk, "Analisis Kesediaan Membayar (Willingness To Pay) Konsumen Terhadap Sayuran Organik Di Pasar Modern Purwokerto Dan Faktor Yang Mempengaruhi”. Jurnal Jurusan Agribisnis Fakultas Pertanian Universitas Jenderal Soedirman, Vol. 17, No. 1, 2020, hh. 40-48.

Hendri dan Roy Setiawan, "Pengaruh Motivasi Kerja dan Kompensasi Terhadap Kinerja Karyawan Di PT.Samudra Bahari Utama”. Jurnal Program Studi
Manajemen Bisnis dan Manajemen Universitas Kristen Petra, Vol.5, No.1, 2017.

Lely Diana Sari Saputri, "Willingness To Pay Mahasiswa FE UNY 2014-2017 Terhadap Makanan Berlabel Halal".Jurnal Ekonomi dan Pendidikan Universitas Negeri Yogyakarta, Vol. 15, No. 1, 2018, hh. 35-42.

Luthfan Hadhi Priambodo dan Mukhamad Najib, “ Analisis Kesediaan Membayar (Willingness To Pay) Sayuran Organik dan Faktor-faktor yang Mempengaruhinya". Jurnal Manajemen dan Organisasi Institut Pertanian Bogor, Vol.5. No.1, April 2014.

Muhammad Fauzi (2010). “ Faktor-faktor Yang Mempengaruhi Kesediaan Membayar Pelanggan Rumah Tangga UPT PAM Kota Metro". Tesis Magister Perencanaan dan Kebijakan Publik. Universitas Indonesia.

Kurniawan, Deny. (2008), "Regresi Linier (Linier Regression). http://ineddeni.wordpress.com. Diakses pada 10 Maret 2021 pukul 19.00 WIB.

Risma Dwi Komala, Nellyaningsih,Dra,MM, “ Tinjauan Implementasi Personal Selling Pada PT.Astra Internasional Daihatsu Astra Biz Center Bandung Pada Tahun 2017’. Jurnal Fakultas Ilmu Terapan Universitas Telkom, Vol.3, No.2, Agustus 2017, hh 330-337.

RR Chyntia Ramadhani Febrita (2017). “Analisis Kesediaan Membayar (Willingness To Pay) Beras Organik (Studi Kasus: Galael Signature di Kota Makassar)". Skripsi S1 Program Studi Agribisnis. Makasar : Fakultas Pertanian Universitas Hasannuddin.

Vickitra Aufanada, dkk, "Kesediaan Membayar Produk Sayuran Organik di Pasar Modern Jakarta Selatan”. Jurnal Program Studi Agribisnis Universitas Diponegoro, Vol.3, No.2, Juli 2017, hh 67-75. 